\title{
Electrochemical behaviour of aluminium in non-aqueous electrolytes over a wide potential range
}

\author{
P. Suresh ${ }^{\mathrm{a}}$, A.K. Shukla ${ }^{\mathrm{a}}$, S.A. Shivashankar ${ }^{\mathrm{b}}$, N. Munichandraiah ${ }^{\mathrm{c}, *}$ \\ ${ }^{\mathrm{a}}$ Solid State and Structural Chemistry Unit, Indian Institute of Science, Bangalore-560 012, India \\ ${ }^{\mathrm{b}}$ Materials Research Centre, Indian Institute of Science, Bangalore-560 012, India \\ ${ }^{\mathrm{c}}$ Department of Inorganic and Physical Chemistry, Indian Institute of Science, Bangalore-560 012, India
}

Received 14 January 2002; accepted 19 March 2002

\begin{abstract}
The electrochemical behaviour of aluminium in $\mathrm{LiClO}_{4}$-propylene carbonate electrolyte is studied by cyclic voltammetry, steady-state polarisation, and ac impedance spectroscopy in the potential range $-0.4-4.2 \mathrm{~V}$ versus $\mathrm{Li} / \mathrm{Li}^{+}$. The open-circuit potential of $\mathrm{Al}$ is $1.57 \mathrm{~V}$ versus $\mathrm{Li} / \mathrm{Li}^{+}$, which is about $0.2 \mathrm{~V}$ above the thermodynamic value of $\mathrm{Al}$ due to the presence of a surface passive film. In the positive potential region, $\mathrm{Al}$ is fairly stable between 1.57 and $3.5 \mathrm{~V}$ versus $\mathrm{Li} / \mathrm{Li}^{+}$owing to the presence of the surface film. Nevertheless, the oxidation of $\mathrm{Al}$ occurs at potentials $>3.5 \mathrm{~V}$ versus $\mathrm{Li} / \mathrm{Li}^{+}$. The ac impedance data are analysed by using a non-linear least-squares fitting procedure, and the surface film resistance is found to be between 498 and $1032 \mathrm{k} \Omega \mathrm{cm}^{-2}$. In the potential range 3.6-4.2 $\mathrm{V}$ versus $\mathrm{Li} / \mathrm{Li}^{+}$, there is a breakdown of the passive film as demonstrated by a decrease in its resistance to $1.2-4.8 \mathrm{k} \Omega \mathrm{cm}^{-2}$. This breakdown accompanies anodic oxidation of Al. Thus, there is a possibility of anodic degradation of the Al substrate that is usually used as the current-collector of positive electrodes of Li-ion batteries, if $\mathrm{Al}$ is exposed to the electrolyte. In the negative potential region, the deposition of uniform and non-dendritic Li occurs, which can be anodically stripped in a quasi-reversible process with high coulombic efficiency. Diffusion of Li into Al results in the formation of a surface layer of Li-Al alloy, as suggested by X-ray diffraction patterns. The quasi-reversible cathodic deposition and anodic stripping of Li with an exchange current density of $0.16 \mathrm{~mA} \mathrm{~cm}^{-2}$ indicates that $\mathrm{Al}$ is useful as a negative electrode in Li-batteries. (C) 2002 Elsevier Science B.V. All rights reserved.
\end{abstract}

Keywords: Aluminium oxidation; Surface film; Lithium deposition; Cyclic voltammetry; Alternating current (ac) impedance

\section{Introduction}

Research and development efforts on high-energy batteries have assumed considerable importance in recent years [1]. The lithium-ion battery has emerged as the most promising energy-storage device for a wide range of applications [2,3]. This battery consists of a lithiated transition metal oxide (e.g. $\mathrm{LiCoO}_{2}$ ) as the positive electrode active material and carbon (e.g. graphite) as the negative electrode active material. The cell is electrochemically active due to intercalation-de-intercalation of $\mathrm{Li}^{+}$ions at both the electrodes. The potential of the positive electrode is about $4.2 \mathrm{~V}$ versus $\mathrm{Li} / \mathrm{Li}^{+}$and that of the negative electrode is close to $0 \mathrm{~V}$ versus $\mathrm{Li} / \mathrm{Li}^{+}$.

The current-collectors generally employed for the positive and negative electrodes are $\mathrm{Al}$ and $\mathrm{Cu}$, respectively. It is noteworthy that the potential of $\mathrm{Al}$ is $1.37 \mathrm{~V}$ versus $\mathrm{Li} / \mathrm{Li}^{+}$, a

\footnotetext{
* Corresponding author. Tel.: +91-80-394-2828; fax: +91-80-360-0683. E-mail address: muni@ipc.iisc.ernet.in (N. Munichandraiah).
}

value that is extremely negative with respect to the positive electrode. Due to the presence of porous active materials on the surface, the potential of $\mathrm{Al}$ wherever it is not covered by the electrode active material shifts to a high positive value. Consequently, it is susceptible to oxidation. Furthermore, if cell reversal, which may happen in the case of a battery due to the mismatch of the capacity of individual cells, occurs, the potential of $\mathrm{Al}$ shifts to negative values where the reduction of $\mathrm{Li}^{+}$ions is possible. An evaluation of electrochemical characteristics of $\mathrm{Al}$ over a wide potential range in non-aqueous media is therefore important. There are few reports on this topic in the literature [4-6]. For example, a bare $\mathrm{Al}$ electrode in a non-aqueous electrolyte has been cycled repeatedly between 3 and $4.2 \mathrm{~V}$ versus $\mathrm{Li} / \mathrm{Li}^{+}$, and the surface morphology examined [4]. Mounds containing $\mathrm{Al}$ and $\mathrm{Al}_{2} \mathrm{O}_{3}$ as well as pits on the surface, have been identified. By measuring the ac impedance response of the electrode, pitting resistance has been shown to increase with the number of electrical cycles. The corrosion behaviour of $\mathrm{Al}$ current-collectors in $\mathrm{Li} /$ polymer batteries has 
been reported by Chen et al. [5]. In contrast to the studies reported in non-aqueous electrolytes [4], $\mathrm{Al}$ has been shown to possess resistance to uniform corrosion in polymer electrolytes during normal battery charging. Large currents of galvanostatic polarisation bring about the breakdown of $\mathrm{Al}_{2} \mathrm{O}_{3}$ films, however, and pitting corrosion occurs. In a study of the anodic oxidation of $\mathrm{Al}$ in propylene carbonate by means of electrochemical measurements, microscopic observations. elemental and gravimetric analyses, it has been found that the formation and growth of the oxide on $\mathrm{Al}$ occurs in the early stages of anodization [6]. Further anodic oxidation leads to the breakdown of part of the oxide film, which results in pitting corrosion. In all these studies, the behaviour of $\mathrm{Al}$ in only the positive potential range has been studied. There are no reports of studies over a wide potential range encompassing both the anodic and cathodic regions in non-aqueous lithium battery electrolytes.

In the present study, the electrochemical behaviour of $\mathrm{Al}$ is investigated in $\mathrm{LiClO}_{4}$-propylene carbonate electrolyte over the potential range $-0.4-4.2 \mathrm{~V}$ versus $\mathrm{Li} / \mathrm{Li}^{+}$. The results suggest that, in the positive potential range, $\mathrm{Al}$ can undergo oxidation at potential values $>3.6 \mathrm{~V}$, accompanied by breakdown of surface film. In the negative potential range on the other hand, deposition of $\mathrm{Li}$ occurs on $\mathrm{Al}$ at close to $0 \mathrm{~V}$ versus $\mathrm{Li} / \mathrm{Li}^{+}$. The deposition of $\mathrm{Li}$ is uniform without the formation of dendrites, and deposition-stripping cycles occur with good coulombic efficiency. The results suggest that $\mathrm{Al}$ is a promising substrate material for $\mathrm{Li}$ electrodes.

\section{Experimental}

Propylene carbonate, $\mathrm{LiClO}_{4}$ and $\mathrm{Li}$ metal were purchased from Aldrich. Propylene carbonate was vacuum distilled at about $120{ }^{\circ} \mathrm{C}$ and treated with molecular sieves of porosity $4 \AA$ A before making solutions. $\mathrm{LiClO}_{4}$ was dried at $100{ }^{\circ} \mathrm{C}$. Lithium electrodes were sectioned out of a ribbon of $0.75 \mathrm{~mm}$ thickness and the surface was abraded before cell assembly. Aluminium electrodes were cut from a high purity $\mathrm{Al}$ sheet of $0.5 \mathrm{~mm}$ thickness polished to a smooth finish, washed copiously with distilled water rinsed with acetone, dried in a vacuum desiccator, and transferred into a dry box.

Preparation of electrolytes and the assembly of cells were performed in an argon atmosphere in a dry box (MBraun model Unilab) with impurities of moisture and oxygen $<10 \mathrm{ppm}$ each. The electrochemical cells were assembled in glass containers with airtight stoppers made of PTFE and provided with electrical leads. The aluminium foil working electrode had an area of $1.2 \mathrm{~cm}^{2}$ exposed to the electrolyte. Lithium foil was used for the auxiliary and reference electrodes. All potential values are reported with respect to the $\mathrm{Li} / \mathrm{Li}^{+}$reference electrode.

Cyclic voltammetry and electrochemical impedance measurements of the cells in three-electrode configuration were performed using an EG\&G PARC potentiostat-galvanostat (model Versastat) and an electrochemical impedance ana- lyser (model 6310), respectively. For galvanostatic deposition and anodic stripping of $\mathrm{Li}$, an electrical circuit that consisted of a regulated dc power source, a high resistance. and an ammetre in series with the electrochemical cell was employed. A high input impedance digital multimetre was used for measuring electrode potentials. X-ray diffraction patterns of the $\mathrm{Al}$ foils were recorded using a Scintag powder X-ray diffractometer (model XDS 2000) with a copper source. Surface morphology was examined with a JEOL scanning electron microscope (model JSM 5600LV). Electrochemical experiments were performed in an air-conditioned room maintained at $20 \pm 1^{\circ} \mathrm{C}$.

\section{Results and discussion}

\subsection{Positive potential range}

The open-circuit potential of $\mathrm{Al}$ is about $1.57 \mathrm{~V}$ versus $\mathrm{Li} /$ $\mathrm{Li}^{+}$, independent of the concentration of $\mathrm{LiClO}_{4}$ in propylene carbonate electrolyte. The cyclic voltammogram of $\mathrm{Al}$ recorded at a scan rate of $0.05 \mathrm{~V} \mathrm{~s}^{-1}$ in the potential range $1.57-4.2 \mathrm{~V}$ in $1 \mathrm{M} \mathrm{LiClO}_{4}$ electrolyte is shown in Fig. 1. During the forward sweep, there is an initial increase in current until the potential reaches about $2.5 \mathrm{~V}$. Following this, the current is nearly invariant between 2.5 and $3.5 \mathrm{~V}$, but starts to increase at about $3.5 \mathrm{~V}$, and reaches a value of about $80 \mu \mathrm{A} \mathrm{cm}^{-2}$ at $4.2 \mathrm{~V}$. This suggests that $\mathrm{Al}$ is anodically stable due to the presence of a surface film at potentials

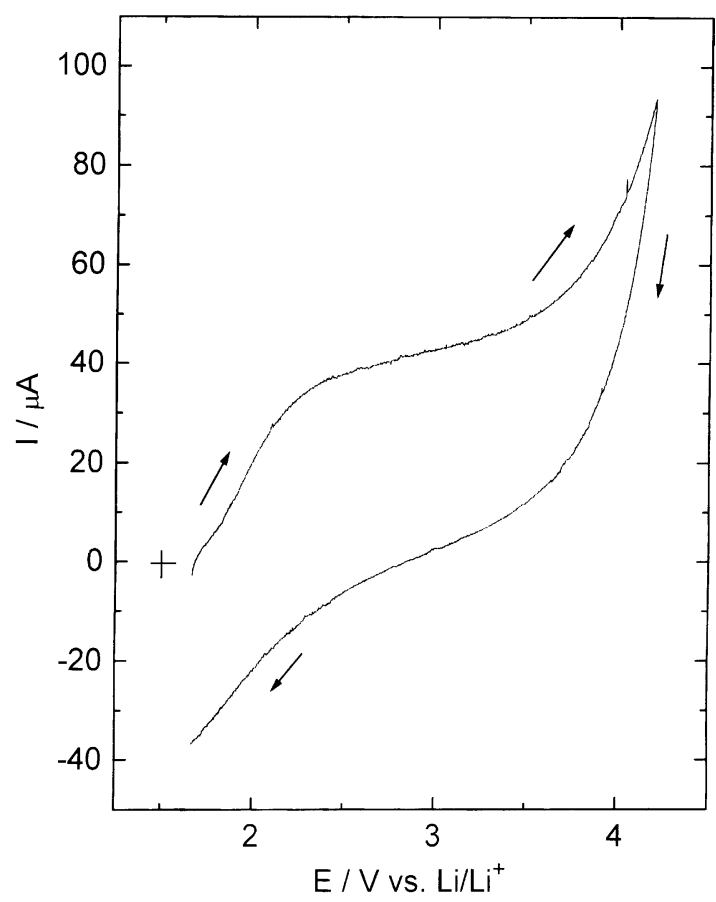

Fig. 1. Cyclic voltammogram at $0.05 \mathrm{~V} \mathrm{~s}^{-1}$ showing anodic behaviour of $\mathrm{Al}$ electrode $\left(\right.$ area $=1.2 \mathrm{~cm}^{-2}$ ) in $1 \mathrm{M} \mathrm{LiClO}_{4}$-propylene carbonate electrolyte. 

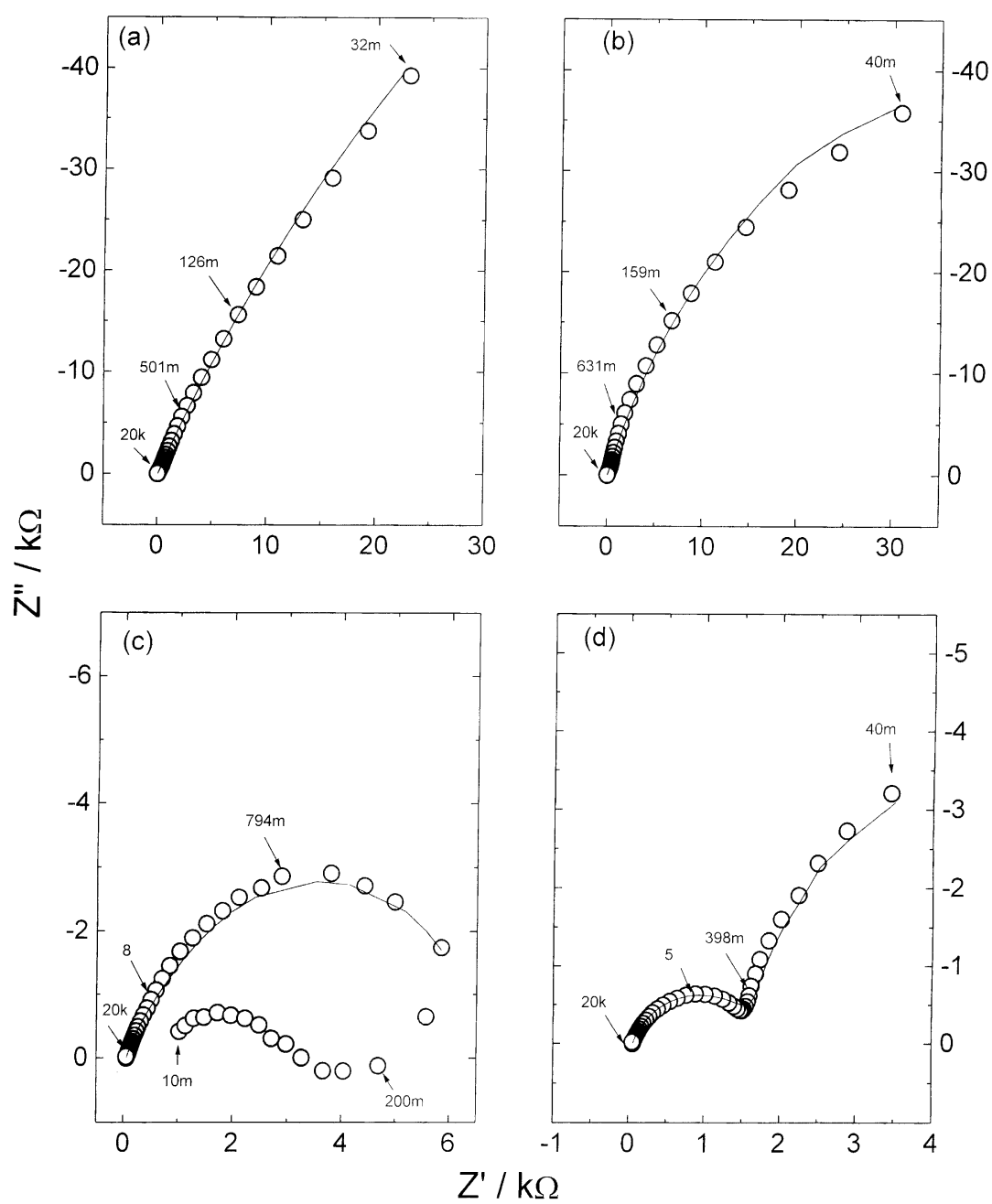

Fig. 2. Nyquist impedance spectra of $\mathrm{Al}$ electrode $\left(\right.$ area $=1.2 \mathrm{~cm}^{2}$ ) at different potentials: (a) 1.57, (b) 3.44, (c) 3.66, (d) 4.22, $\mathrm{V}$ versus Li/Li ${ }^{+}$. Experimental data are shown as symbols and simulated spectra from NLLS fit results as curves. Frequency values $(\mathrm{Hz})$ of some data points are shown.

$<3.5 \mathrm{~V}$ and that it undergoes oxidation above this potential, i.e.,

$\mathrm{Al} \rightarrow \mathrm{Al}^{3+}+3 \mathrm{e}^{-}$

There are two possibilities for the presence of a surface film on Al. First, there can be a native oxide film prior to cell assembly in the non-aqueous electrolyte. Second, the oxidation current between 1.57 and $2.5 \mathrm{~V}$ (Fig. 1) is possibly due to oxidation of $\mathrm{Al}$ to $\mathrm{Al}^{3+}$ producing $\mathrm{Al}_{2} \mathrm{O}_{3}$ or $\mathrm{Al}_{2}\left(\mathrm{CO}_{3}\right)_{3}$ on the surface akin to the mechanism of formation of surface films on $\mathrm{Li}$ [2]. The formation of $\mathrm{Al}_{2} \mathrm{O}_{3}$ films on $\mathrm{Al}$ in nonaqueous electrolytes has been reported [4,7]. As a result, the Al electrode acquires surface passivity towards anodic oxidation up to about $3.5 \mathrm{~V}$. At potentials $>3.5 \mathrm{~V}$, reaction 1 occurs via the breakdown of the surface oxide film. This is reflected by a decrease in the resistance of the $\mathrm{Al}$ electrodes, as discussed below.

Electrochemical impedance spectra of $\mathrm{Al}$ measured at different potential values between 1.5 and $4.2 \mathrm{~V}$ (Fig. 2) corroborate the cyclic voltammetric data. Nyquist plots (Fig. 2) of the impedance spectra between 1.5 and $3.5 \mathrm{~V}$ do not take the shape of semicircles. These data may be explained with the help of equivalent circuit shown in Fig. 3(a), where the resistance $\left(R_{1}\right)$ and capacitance $\left(C_{1}\right)$ of the surface layer are considered to exist in parallel combination and the solution resistance $\left(R_{0}\right)$ is in series.
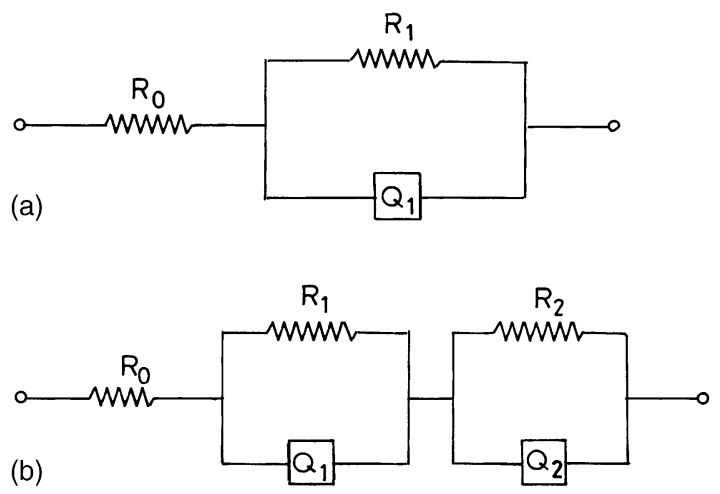

Fig. 3. Equivalent circuits used for NLLS fitting of experimental data (see text for symbols) of $\mathrm{Al}$ electrode. 
Table 1

Impedance parametre obtained by NLLS fit at different potentials

\begin{tabular}{|c|c|c|c|c|c|c|c|c|}
\hline \multirow[t]{2}{*}{ Potential (V) } & \multirow[t]{2}{*}{ Equivalent circuit } & \multicolumn{7}{|c|}{ Parameters } \\
\hline & & $R_{0}(\Omega)$ & $R_{1}(\Omega)$ & $Q_{1}$ & $n_{1}$ & $R_{2}(\Omega)$ & $Q_{2}$ & $n_{2}$ \\
\hline 1.57 & $R(\mathrm{RQ})$ & 55.7 & $4.15 \times 10^{5}$ & $7.04 \times 10^{-5}$ & 0.75 & & & \\
\hline 1.85 & $R(\mathrm{RQ})$ & 57.0 & $4.84 \times 10^{5}$ & $6.43 \times 10^{-5}$ & 0.76 & & & \\
\hline 2.33 & $R(\mathrm{RQ})$ & 57.9 & $5.39 \times 10^{5}$ & $6.09 \times 10^{-5}$ & 0.78 & & & \\
\hline 2.80 & $R(\mathrm{RQ})$ & 57.9 & $7.98 \times 10^{5}$ & $4.37 \times 10^{-5}$ & 0.81 & & & \\
\hline 3.05 & $R(\mathrm{RQ})$ & 62.5 & $8.58 \times 10^{5}$ & $4.99 \times 10^{-5}$ & 0.82 & & & \\
\hline 3.44 & $R(\mathrm{RQ})$ & 58.3 & $1.34 \times 10^{5}$ & $5.10 \times 10^{-5}$ & 0.80 & & & \\
\hline 3.66 & $R(\mathrm{RQ})(\mathrm{RQ})$ & 57.5 & $4.84 \times 10^{3}$ & $4.55 \times 10^{-5}$ & 1 & $1.59 \times 10^{3}$ & $7.04 \times 10^{3}$ & 0.73 \\
\hline 3.85 & $R(\mathrm{RQ})(\mathrm{RQ})$ & 59.0 & $1.02 \times 10^{3}$ & $2.89 \times 10^{-5}$ & 0.83 & $8.28 \times 10^{3}$ & $1.59 \times 10^{3}$ & 1.00 \\
\hline 4.12 & $R(\mathrm{RQ})(\mathrm{RQ})$ & 57.8 & $1.58 \times 10^{3}$ & $3.62 \times 10^{-5}$ & 0.80 & $2.81 \times 10^{3}$ & $1.81 \times 10^{3}$ & 1.00 \\
\hline 4.22 & $R(\mathrm{RQ})(\mathrm{RQ})$ & 56.8 & $1.65 \times 10^{3}$ & $3.96 \times 10^{-5}$ & 0.79 & $5.95 \times 10^{3}$ & $1.04 \times 10^{3}$ & 1.00 \\
\hline
\end{tabular}

Since impedance parameters such as the capacitance are usually distributed and their values vary over the electrode surface, a constant phase element (CPE) $Q_{1}$ is considered in place of $C_{1}$ [8]. The impedance spectra in the potential region between 1.57 and $3.5 \mathrm{~V}$ have been analysed by means of a non-linear least-squares (NLLS) fitting program due to Boukamp [9]. Values of the parameters obtained at several potentials are given in Table 1 . The solution resistance $\left(R_{0}\right)$ is nearly invariant at all potentials, whereas the surface film resistance $\left(R_{1}\right)$ increases from $498 \mathrm{k} \Omega \mathrm{cm}^{-2}$ at $1.57 \mathrm{~V}$ to $1032 \mathrm{k} \Omega \mathrm{cm}^{-2}$ at $3.05 \mathrm{~V}$. As the value of $R_{1}$ is high the impedance data are nearly parallel to the imaginary axis (Fig. 2(a) and (b)) and suggest a capicitive behaviour. This is clearly reflected in the Bode form of the impedance data (not shown) where $\log$ (impedance, $(I Z \mid))$ in the frequency region from $100 \mathrm{kHz}$ to $100 \mathrm{~Hz}$ decreases linearly with log (frequency) with a slope of about 0.9 which is close to the value of unity for a pure capacitor.

At about $3.6 \mathrm{~V}$, the impedance Nyquist spectrum has the shape of a semicircle with a positive loop in the low-frequency region Fig. 2(c) As observed with cyclic voltammetry, oxidation of $\mathrm{Al}$ starts around this potential (Fig. 1). As a lowfrequency positive loop in an electrochemical process is reported to be due to adsorbed species $[10,11]$ such a loop may be attributed in the case of $\mathrm{Al}$ to the adsorption of $\mathrm{Al}$ species. Thus, the distorted capacitive semicircle in Fig. 2(c) is due to an overlap of the impedance of the anodic oxidation of $\mathrm{Al}$ and the impedance of the surface film. The spectrum (Fig. 2(c)) omitting the low-frequency loop is represented by the equivalent circuit shown in Fig. 3(b), where the chargetransfer resistance $\left(R_{2}\right)$ of reaction (1) and a CPE $\left(Q_{2}\right)$ corresponding to the double-layer capacitance $\left(C_{2}\right)$ are considered to exist in parallel which, in turn, is in series with the rest of the sub-circuit. The semicircle is distorted due to overlap of the $R_{1} C_{1}$ and $R_{2} C_{2}$ time constants. At potentials $>3.6 \mathrm{~V}$ the data resolve into a pair of semicircles (Fig. 2(d)) due to decrease in the $R_{2} C_{2}$ time constant as a result of an increased rate of reaction (1). The impedance parameters obtained by fitting the data in the potential range 3.5-4.2 V are included in Table 1. It is found that the ohmic resistance
$\left(R_{0}\right)$ is nearly constant throughout the positive potential range. The resistance $\left(R_{1}\right)$ of the surface film on $\mathrm{Al}$ is between 498 and $960 \mathrm{k} \Omega \mathrm{cm}^{-2}$ in the potential range up to $3 \mathrm{~V}$, but decreases to $1.2-4.8 \mathrm{k} \Omega \mathrm{cm}^{-2}$ in range $3.6-4.2 \mathrm{~V}$. This decrease is attributed to breakdown of the surface film on $\mathrm{Al}$ which allows the oxidation of $\mathrm{Al}$ (reaction 1) to take place. The decreases in resistance also supports the cyclic voltammetric results, which have indicated an increase in current due to reaction (1) at about $3.5 \mathrm{~V}$. The charge-transfer resistance $\left(R_{2}\right)$ of reaction (1) decreases with increase in potential (Table 1) which suggests an increase in the reaction rate.

\subsection{Negative potential range}

Electrochemical impedance spectra of $\mathrm{Al}$ were recorded at several potentials between the open-circuit potential 1.57 and $-0.4 \mathrm{~V}$. The impedance behaviour of $\mathrm{Al}$ is capacitive, similar to the data of Fig. 2(a) and (b) down to about $0 \mathrm{~V}$ and statisfies the equivalent circuit shown in Fig. 3(a). The data at $0 \mathrm{~V}$ and more negative potentials, however, take the shape of semicircles due to deposition of $\mathrm{Li}$ according to:

$\mathrm{Li}^{+}+\mathrm{e}^{-} \rightleftarrows \mathrm{Li}$

The impedance of $\mathrm{Al}$ at $0 \mathrm{~V}$ is shown in Fig. 4 as a Nyquist plot. A comparison of Figs. 2 and 4 suggests that the impedance in the latter is lower than that in the former by several orders of magnitude. Under the conditions of deposition of $\mathrm{Li}$ on $\mathrm{Al}$, the impedance spectrum corresponds to an equivalent circuit similar to that shown in Fig. 3(a) with $R_{3}$ and $Q_{3}$ in place of $R_{1}$ and $Q_{1}$ where the charge-transfer resistance $\left(R_{3}\right)$ of reaction (2) is considered in parallel with $Q_{3}$. The CPE $Q_{3}$ is used in place of the double-layer capacitance $\left(C_{3}\right)$ of the $\mathrm{Li}($ on $\mathrm{Al}) /$ electrolyte interface. The impedance spectrum (Fig. 4) has been analysed by the NLLS fitting procedure and the values of the parameters are included in the caption of Fig. 4 . The values of the chargetransfer resistance $\left(R_{3}\right)$ obtained is $47.4 \Omega \mathrm{cm}^{-2}$ which is a value similar to that obtained from dc polarisation data and the exchange current density of reaction (2), as calculated in the manner described below. 


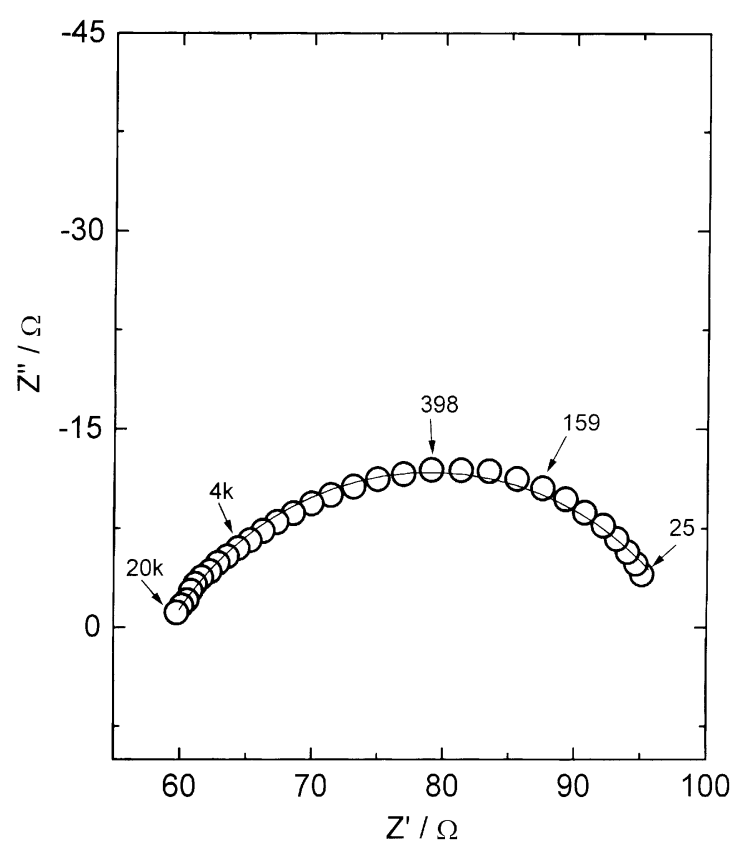

Fig. 4. Nyquist impedance spectrum of $\mathrm{Al}$ electrode $\left(\operatorname{area}=1.2 \mathrm{~cm}^{2}\right.$ ) at $0 \mathrm{~V}$ in $1 \mathrm{M} \mathrm{LiClO}_{4}$-propylene carbonate electrolyte. Experimental data are shown as symbols and simulated spectrum from NLLS fit results as a curve. Values of fit parameters are: $R_{0}=59.2 \Omega, R_{3}=39.5 \Omega, Q_{3}=1.17 \times 10^{-4}$, and $n_{3}=0.681$. Frequency values $(\mathrm{Hz})$ of some data points are shown.

The cathodic deposition of $\mathrm{Li}$ on $\mathrm{Al}$ surface was further studied by cyclic voltammetry. The cyclic voltammograms recorded between 2.5 and $-0.6 \mathrm{~V}$ are presented in Fig. 5. During the forward sweep, current starts increasing at about

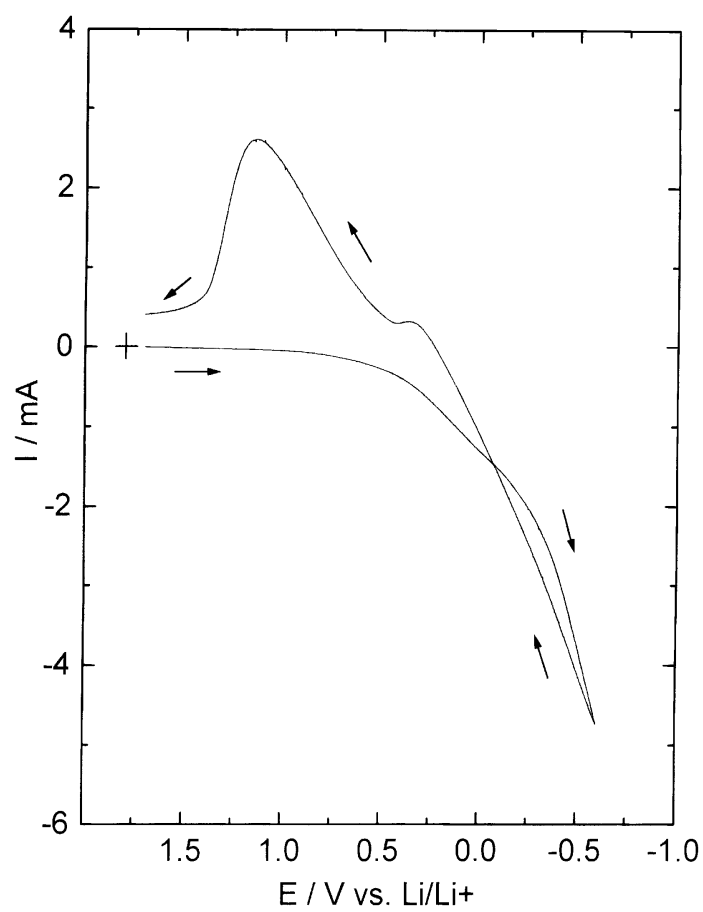

Fig. 5. Cyclic voltammogram at $0.05 \mathrm{~V} \mathrm{~s}^{-1}$ showing cathodic behaviour of $\mathrm{Al}$ electrode $\left(\operatorname{area}=1.2 \mathrm{~cm}^{2}\right.$ ) in $1 \mathrm{M} \mathrm{LiClO}_{4}$-propylene carbonate electrolyte.
$0 \mathrm{~V}$ and continues without reaching any peak. The large magnitude of the cathodic current is due to reduction of $\mathrm{Li}^{+}$ (reaction 2) and results in the deposition of $\mathrm{Li}$ on the surface. The absence of a current peak in the cathodic direction suggests that the deposition of $\mathrm{Li}$ is under charge-transfer control. The surface of Al turns grey in this region. During the reverse sweep, the current peaks at about $0.8 \mathrm{~V}$, which is attributed to diffusion-limited anodic oxidation of $\mathrm{Li}$ on the Al surface (reverse of reaction 2). Thus, the deposition of $\mathrm{Li}$ on $\mathrm{Al}$ occurs as a charge-transfer-controlled process whereas the reverse reaction occurs as a diffusion-limited process. It is interesting to note that, upon completion of the potential cycle, the surface of the Al remains grey, which indicates the presence of $\mathrm{Li}$ on $\mathrm{Al}$. This suggests that the amount of $\mathrm{Li}$ deposited in the forward sweep is not completely oxidised back into the electrolyte. This conclusion is supported by the fact that the charge associated with the anodic current is less than the cathodic charge of $\mathrm{Li}$ deposition.

The cathodic deposition of $\mathrm{Li}$ on $\mathrm{Al}$ was carried out galvanostatically at a current of $0.83 \mathrm{~mA} \mathrm{~cm}^{-2}$ for several hours. It was found that the deposition was smooth and uniform, without any dendrites. Under similar experimental conditions with $\mathrm{Li}$ instead of $\mathrm{Al}$, the $\mathrm{Li}$ deposited was spongy and dendritic. Subsequently, Li on Al electrode was stripped by anodic discharge. and then the galvanostatic chargedischarge cycling continued. The variation of electrode

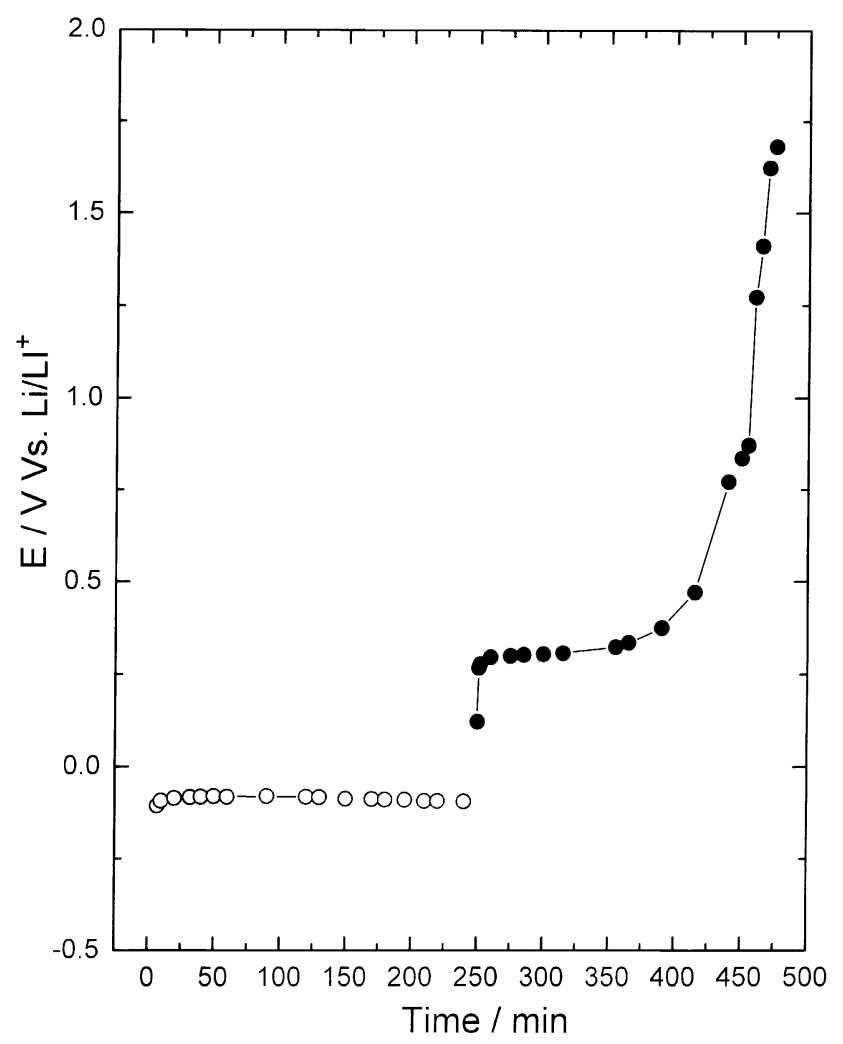

Fig. 6. Variation of $\mathrm{Al}$ electrode potential during deposition $(\mathrm{O})$ and, stripping (O) of $\mathrm{Li}$ at current density of $0.83 \mathrm{~mA} \mathrm{~cm}^{-2}$ in $1 \mathrm{M} \mathrm{LiClO}_{4}$ in propylene carbonate electrolyte. 


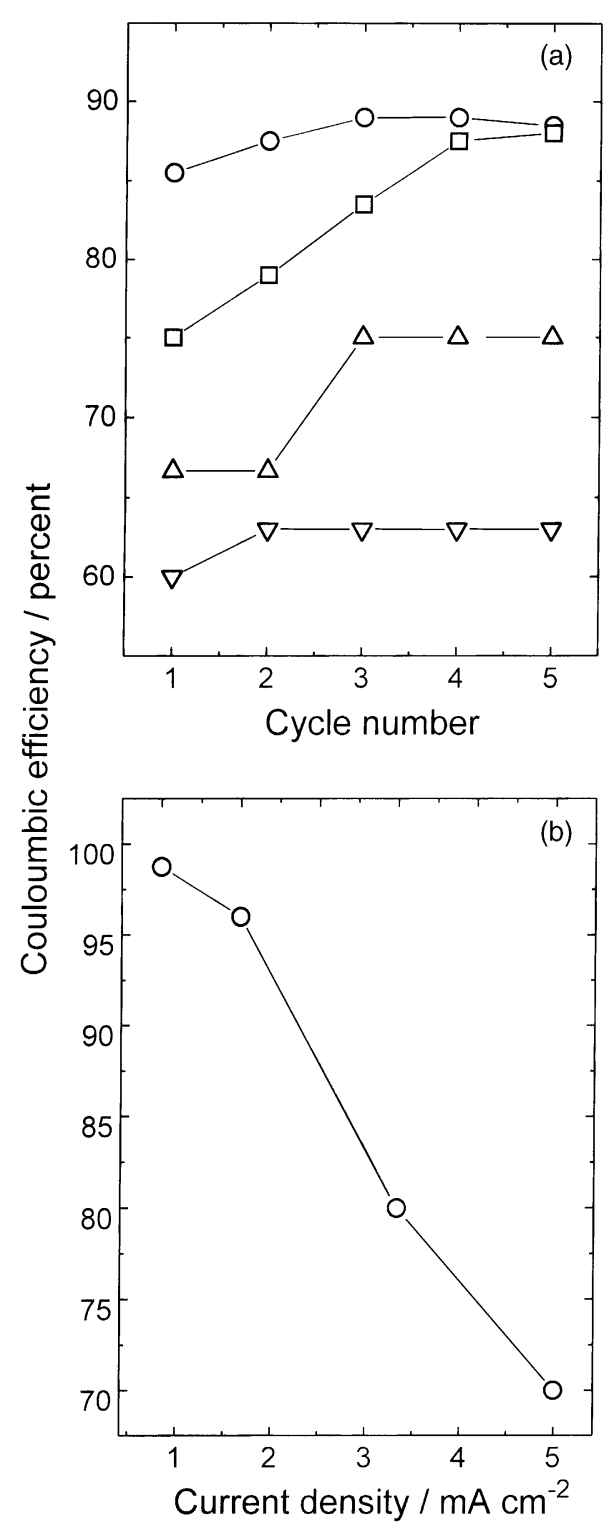

Fig. 7. Coulombic efficiency of anodic stripping of $\mathrm{Li}$ on $\mathrm{Al}$ surface (a) as function of cycle number at current density of $(\bigcirc) 0.83,(\square) 1.66,(\triangle)$ 3.33 , and $(\nabla) 5.0 \mathrm{~mA} \mathrm{~cm}^{-2}$ and; (b) as function of current density. Data in (b) correspond to fifth cycle.

potential during the charge-discharge cycle is shown in Fig. 6. The electrode was subjected to several cycles and the coulombic efficiency of discharge is shown as a function of cycle number in Fig. 7. At a current density of $0.83 \mathrm{~mA} \mathrm{~cm}^{-2}$, the efficiency is about $85 \%$ for the first cycle, and increases to and remains at $90 \%$ from the third cycle onwards. It is noteworthy that the deposition of Li during charging is always uniform and free from dendrites over several cycles.

It is generally believed that the development of rechargeable Li batteries has been hampered by the dendritic and spongy deposition of $\mathrm{Li}$ on the Li substrate during chargedischarge cycling. This problem has led to the development of a carbon-based negative electrode which allows reversible intercalation-de-intercalation of $\mathrm{Li}$ within its layers. The capacity of carbon, however, is about $340 \mathrm{mAh} \mathrm{g}^{-1}$ (corresponding to the composition $\mathrm{C}_{6} \mathrm{Li}$ ) which is considerably $<3.8 \mathrm{Ah} \mathrm{g}^{-1}$ of pure Li metal. In order to utilise the highcapacity Li metal as the negative electrode for rechargeable batteries, attempts have been made to reduce the dendritic deposition [12-15]. Dendrite-free deposition of $\mathrm{Li}$ on a $\mathrm{Ni}$ substrate in the presence of $5 \mathrm{mM} \mathrm{HF}$ in the electrolyte over repeated cycles has been reported [12] The use of $\mathrm{Li}-\mathrm{Al}$ alloy instead of pure Li has also been studied [13,14]. In a recent study [15], Al films of thickness in the range 0.1$1 \mu \mathrm{m}$ have been deposited by thermal evaporation on copper substrates and evaluated as negative electrodes for $\mathrm{Li}$-ion cells. In the present study, the deposition of $\mathrm{Li}$ on $\mathrm{Al}$ foil electrodes is found to be free from dendrites during several cycles which shows that $\mathrm{Al}$ can be used as the negative electrode in rechargeable $\mathrm{Li}$ batteries.

$\mathrm{An} \mathrm{Al} \mathrm{electrode} \mathrm{was} \mathrm{removed} \mathrm{from} \mathrm{the} \mathrm{cell} \mathrm{after} \mathrm{several}$ cycles, washed with water for oxidation of any Li present on the surface, and dried. The electrode still remains grey which suggests that the colour is not due to metallic $\mathrm{Li}$ on the $\mathrm{Al}$ surface, but to $\mathrm{Li}$ which has penetrated into $\mathrm{Al}$ and caused the formation of $\mathrm{Li}-\mathrm{Al}$ alloy. This was confirmed by comparing the XRD patterns of unused $\mathrm{Al}$ and grey $\mathrm{Al}$ specimens (Fig. 8). The XRD pattern of the Al specimen (Fig. 8(a)) matches the standard pattern of Al. There are, however, additional peaks at $2 \theta$ values of $24.2,40.1,47.5$,

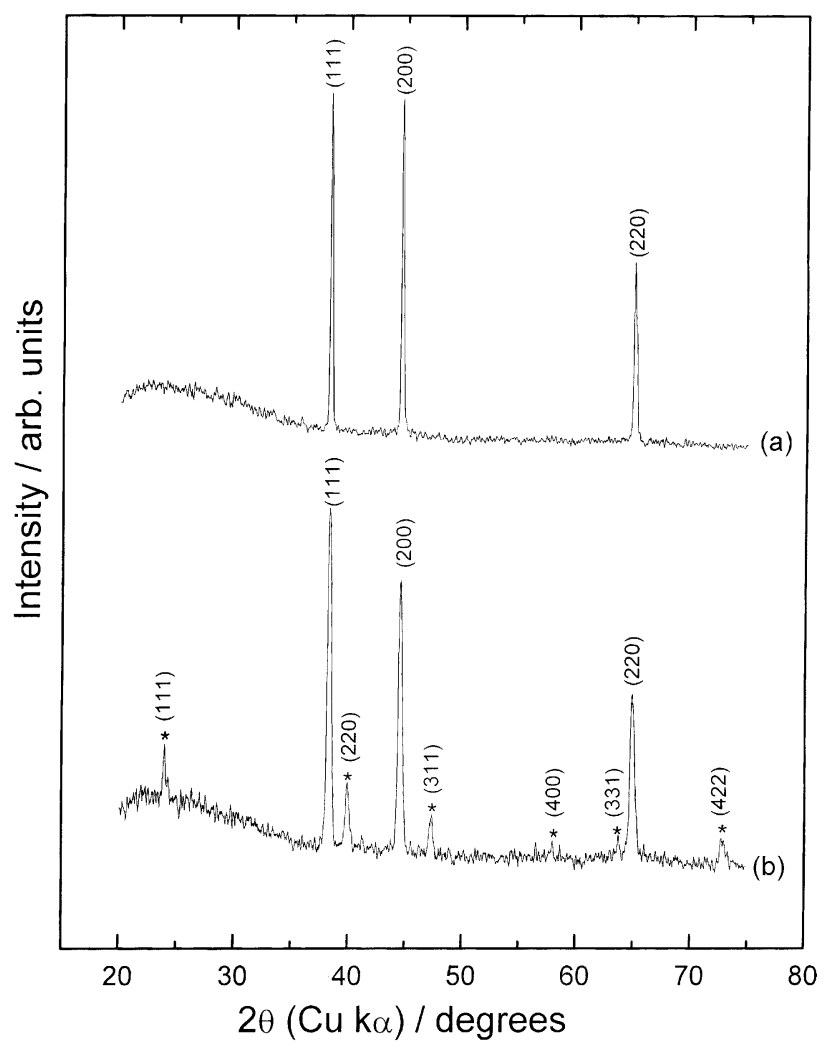

Fig. 8. XRD patterns for (a) Al (b) Li-Al alloy. Reflections marked (*) $\mathrm{Li}-\mathrm{Al}$ alloy. 

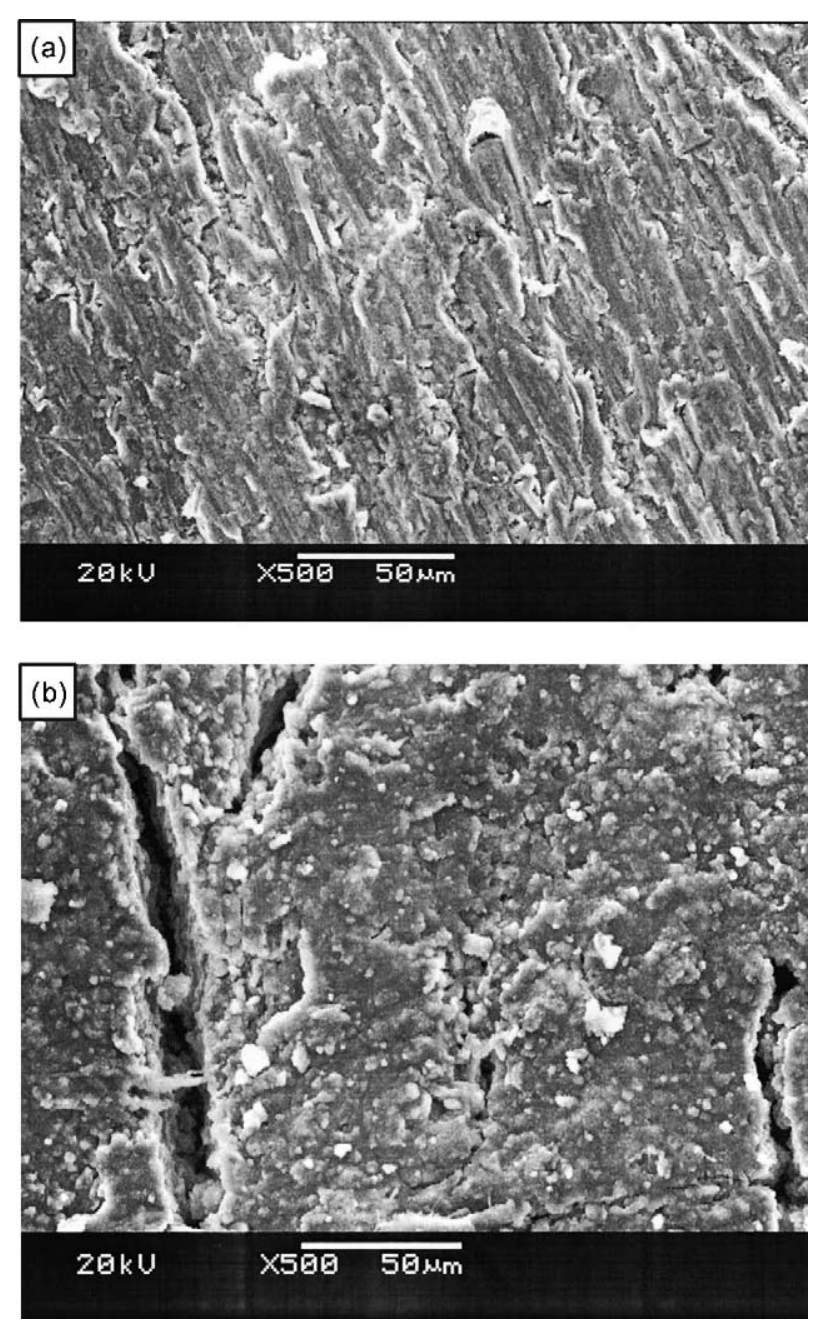

Fig. 9. Scanning electron micrographs of (a) pure $\mathrm{Al}$ foil (b) Li-Al alloy.

58.1, 63.8 and $72.9^{\circ}$ in Fig. 8(b) which correspond to the $\mathrm{Li}-\mathrm{Al}$ composition. The surface of the $\mathrm{Al}$ specimen was examined with a scanning electron microscope (Fig. 9). The micro-cracks which are distributed uniformly over the entire surface (Fig. 9(b)) are due to stresses that develop on insertion of $\mathrm{Li}$ into $\mathrm{Al}$ and result in the formation of alloy. Micro-cracks of this type are absent in an unused $\mathrm{Al}$ specimen (Fig. 9(a)).

The electrodeposition of $\mathrm{Li}$ on $\mathrm{Al}$, and its anodic oxidation processes, (reaction 2) was studied by Tafel and linearpolarisation techniques in stirred electrolytes. Typical data are shown in Fig. 10. The relationship between the current density $(i)$ and the overpotential $(\eta)$ for reaction (2) is given by:

$i=i_{\mathrm{o}}\left(\exp \left(\frac{-\alpha F \eta}{R T}\right)-\exp \left(\frac{(1-\alpha) F \eta}{R T}\right)\right)$

where $i_{\mathrm{o}}$ is the exchange current density $\alpha$ the energy-transfer coefficient other symbols have their usual meanings. The cathodic and anodic Tafel regions are linear with slopes of about $0.27 \mathrm{~V} \mathrm{decade}^{-1}$ Thus, the average value of $\alpha$ becomes
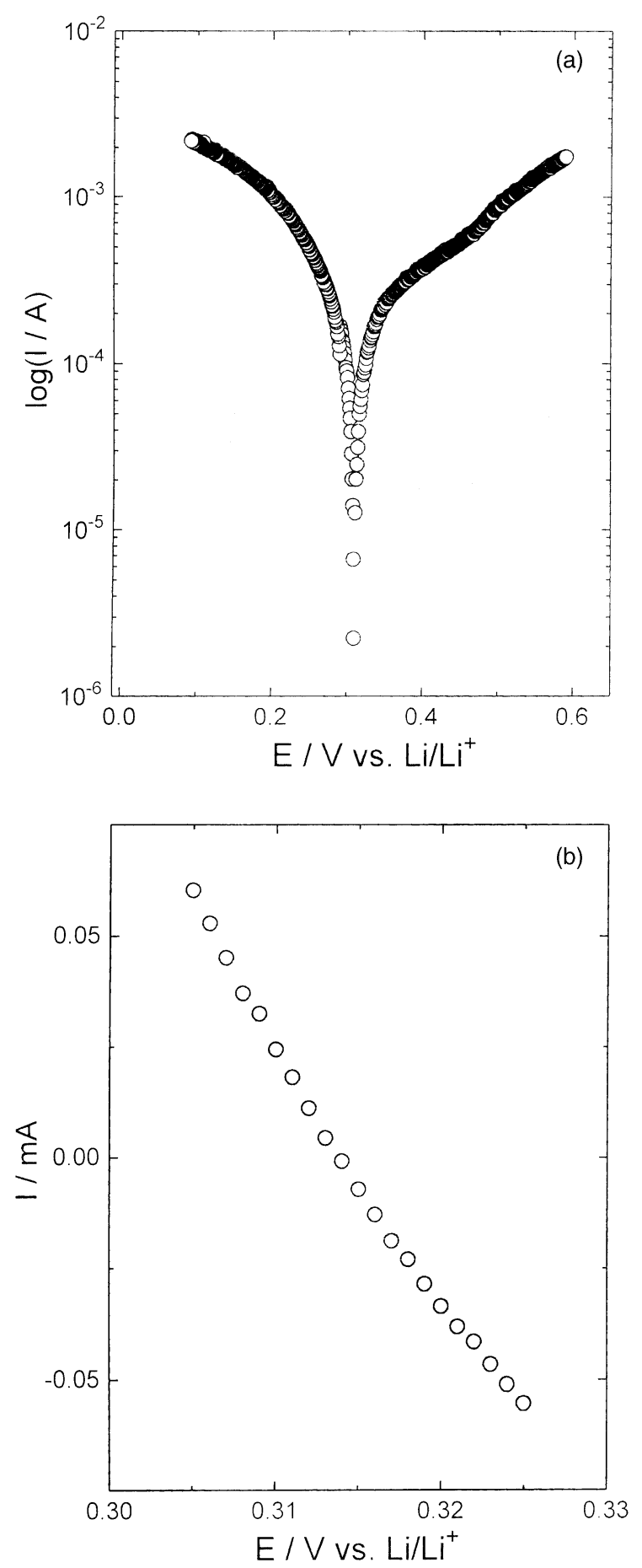

Fig. 10. (a) Tafel, (b) linear-polarisation curves for $\mathrm{Al}$ electrode $\left(\right.$ area $\left.=1.2 \mathrm{~cm}^{2}\right)$ in $1 \mathrm{M} \mathrm{LiClO}_{4}$ in propylene carbonate electrolite.

0.22 and suggests that reaction (5) is quasi-reversible. The value $i_{\mathrm{o}}$ obtained by extrapolation of the Tafel region to $\eta=0$ is about $0.16 \mathrm{~mA} \mathrm{~cm}^{-2}$. The slope of linear-polarisation data (Fig. 10(b)) also provides $i$ through:

$\frac{\mathrm{d} \eta}{(\mathrm{d} i)_{\eta=0}}=\frac{R T}{i_{\mathrm{o}} F}$ 
Eq. (4) is obtained from Eq. (3) by linearizing exponential terms at low values of $\eta$. The value of $i_{\mathrm{o}}$ evaluated from the data of Fig. 10 (b) is $0.14 \mathrm{~mA} \mathrm{~cm}^{-2}$, which is close to the value obtained from Tafel data. The above results support the suitability of $\mathrm{Al}$ as the negative electrode in non-aqueous Li batteries.

\section{Conclusions}

The electrochemical behaviour of $\mathrm{Al}$ in $\mathrm{LiClO}_{4}$-propylene carbonate electrolyte is studied by cyclic voltammetry, steady-state polarisation and ac impedance spectroscopy over the potential range $-0.4-4.2 \mathrm{~V}$ versus $\mathrm{Li} / \mathrm{Li}^{+}$. In the positive potential region $\mathrm{Al}$ is fairly stable between 1.57 and $3.5 \mathrm{~V}$ owing to the presence of a surface film. Nevertheless, oxidation of $\mathrm{Al}$ occurs at potentials $>3.5 \mathrm{~V}$. From ac impedance measurements, the value for the surface film resistance is found to be between 498 and $1032 \mathrm{k} \Omega \mathrm{cm}^{-2}$. In the potential range from 3.6 to $4.2 \mathrm{~V}$, there is breakdown of the passive film which results in a decrease in its resistance to $1.2-48 \mathrm{k} \Omega \mathrm{cm}^{-2}$. In the negative potential region, the deposition of uniform and non-dendritic Li occurs. This deposit can be anodically stripped in a quasi-reversible process with high coulombic efficiency. Diffusion of Li into $\mathrm{Al}$ results in the formation of a surface layer of $\mathrm{Li}-\mathrm{Al}$ alloy. The quasi-reversible, dendrite-free, cathodic deposition and anodic stripping of Li with an exchange current density of $0.16 \mathrm{~mA} \mathrm{~cm}^{-2}$ suggests that $\mathrm{Al}$ may be useful as negative electrode for Li batteries.

\section{Acknowledgements}

We thank the Ministry of Non-Conventional Energy Sources, Government of India, for financial support.

\section{References}

[1] J.P. Gabano, Lithium batteries, Academic Press, London, 1983, p. 1.

[2] G. Pistoia, Lithium Batteries-New Materials, Developments and Perspectives, Elsevier, Amsterdam, 1994, p. 1.

[3] D. Linden, Handbook of Batteries, McGraw Hill, New York, 1995, p. 14.1 .

[4] J.W. Braithwaite, A. Gonzales, G. Nagasubramanian, S.J Lucero, D.E. Peebles, J.A. Ohlhausen, W.R. Cieslak, J. Electrochem. Soc. 146 (1999) 448.

[5] Y. Chen, T.M. Devine, J.W. Evans, O.R. Monteiro, I.G. Brown, J. Electrochem. Soc. 146 (1999) 1310.

[6] J. Kawakita, K. Kobayashi, J. Power Sources 90 (2000) 182.

[7] M. Ue, F. Mizutani, S. Takeuchi, N. Sato, J. Electrochem. Soc. 144 (1997) 3743.

[8] J.R. Macdonald, Impedance Spectroscopy, John Wiley \& Sons, New York, 1987, p. 84.

[9] B.A. Boukamp, Equivalent Circuit Manual, University of Twente, AE Enechede, 1989, p. 1.

[10] R.D. Armstrong, M. Henderson, J. Electroanl. Chem. 40 (1972) 121.

[11] G. Grish Kumar, N. Munichandraiah, J. Solid State Electrochem. 5 (2001) 8 .

[12] K. Kanamura, S. Shiraishi, Z. Takehara, J. Electrochem. Soc. 141 (1994) L108.

[13] M. Winter, J.O. Besenhard, Electrochem. Acta 45 (1999) 31.

[14] D. Fauteux, R. Koksbang, J. Appl. Electrochem. 23 (1993) 1.

[15] Y. Hamon, T. Brousse, F. Jousse, P. Topart, P. Buvat, D.M. Schleich, J. Power Sources 97-98 (2001) 185. 